Article

\title{
How Does the Color of Restorative Material Change during Exposure to Dietary Liquids Due to the Acquisition of a Discolored Layer?
}

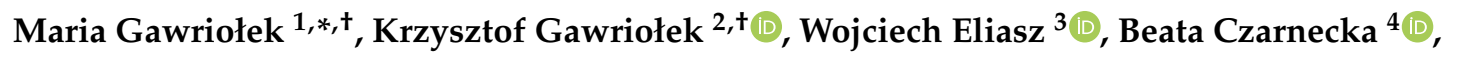 \\ Elżbieta Paszynska ${ }^{1}$ (D) and Marek Sikorski ${ }^{5}$ (D) \\ 1 Department of Integrated Dentistry, Poznan University of Medical Sciences, 60-812 Poznan, Poland; \\ paszynska@ump.edu.pl \\ 2 Department of Temporomandibular Disorders, Poznan University of Medical Sciences, \\ 60-812 Poznan, Poland; krzysztofgawriolek@ump.edu.pl \\ 3 Department of Conservative Dentistry and Endodontics, Poznan University of Medical Sciences, \\ 60-812 Poznan, Poland; weliasz@ump.edu.pl \\ 4 Department Biomaterials and Experimental Dentistry, Poznan University of Medical Sciences, \\ 60-812 Poznan, Poland; czarnecka@ump.edu.pl \\ 5 Faculty of Chemistry, Adam Mickiewicz University, 61-614 Poznan, Poland; sikorski@amu.edu.pl \\ * Correspondence: m.gawriolek@gmail.com \\ + These authors contributed equally to this work.
}

Received: 18 July 2020; Accepted: 2 September 2020; Published: 7 September 2020

\begin{abstract}
Background: The aim of the paper is to determine how selected staining liquids affect color stability and reflectance of six composite and compomer dental materials. (2) Methods: Six dental materials were chosen for this study: G-aenial (GC), Filtek Z550 (3M), Herculite XRV Ultra (Kerr), Compoglass (Ivoclar Vivadent), Dyract Extra (Dentsply), and Dyract Flow (Dentsply). Ten staining liquids were used (distilled water, tea, tea with sugar, coffee, coffee with sugar, Coca-Cola ${ }^{\circledR}$, orange and currant juices, soy sauce, and wine). Staining was carried out at $37^{\circ} \mathrm{C}$. The measurements of the color difference $(\Delta E)$ and the color parameters were carried out on a Konica Minolta CM5 spetrocolorimeter at different staining times $(1,2,4,8,24,48,72$, and $168 \mathrm{~h})$. The resulting color change of the dental materials upon staining is presented as plots of $\Delta E$, diffuse-reflection spectra, and Maxwell's triangle. (3) Results: Significant changes in lightness $(\Delta L)$ along with changes in the total color were observed for most materials. Color change was more pronounced in compomers than in composites. (4) Conclusions: Most materials change their color from light cream to light-brown and reddish after exposure to selected staining liquids.
\end{abstract}

Keywords: color; dental materials; spectrophotometry

\section{Introduction}

Smile is one of the first interactions between humans and constitutes an important factor for any future relation. Cosmetic dentistry is an essential part of dental services provided nowadays for patients of all ages. Changes in teeth structure, including their color, shape, and restorations (in particular, composite resin) are among the most popular procedures provided by dentists. However, all dental materials are exposed to organic pigments present in foods and drinks, which may cause their irreversible discoloration upon prolonged contact due to formation of a coated, colored layer. In order to discuss these changes, one has to take a closer look at the methodology of color assessment.

The Commission Internationale de l'Eclairage (CIE) $L^{*} a^{*} b^{*}(\mathrm{Lab})$ system is one of the most accurate systems for color discrimination used in Europe. At the same time, the NBS system (National Bureau 
of Standards) is widely used in the USA with a number of norms that modified and unified the CIE Lab system. One of the first studies of color of dental materials was published by Yamamoto in the 1980s [1,2]. In the CIE Lab system, color is described by the three orthogonal color coordinates: $L^{*}$, $a^{*}$, and $b^{*}$. Here, the $L^{*}$ axis is normal to the $a^{*}$ and $b^{*}$ axes, giving information on the lightness, with the value of 0 corresponding to black, and 100 to white. At the same time, the values on the $a^{*}$ axis, which is normal to the $b^{*}$ axis, may be either positive or negative. The positive values of $a^{*}$ indicate red color contribution, and the negative values indicate green color contribution. Similarly, the values of the $b^{*}$ coordinate may be either positive and negative, with positive values indicating yellow color contribution, and negative values indicating blue color contribution.

The values of the color difference noticeable to an observer depend on the observer: (i) $\Delta E<2.0$-imperceptible differences or differences noticeable by an experienced observer; (ii) $2.1<\Delta E<3.5$ : slightly perceptible differences; (iii) $3.6<\Delta E<5.0$ : clearly perceptible differences; (iv) $\Delta E>5$ : pronounced color differences [3]. The threshold of color difference perception by an average, although trained, observer equals $\Delta E=\sqrt{ } 3 \approx 1.7$ in the space of the $L^{*}, a^{*}, b^{*}$ coordinates as defined by the CIE Lab system. Generally, the change in each of these coordinates by one unit corresponds to the threshold in the color difference perception. However, the threshold of the color difference precision is variously defined in literature as $\Delta E$ between 1 and 2 by Knispel and Tung, $\Delta E=3.7$ by Haselton, and $\Delta E=1.5$ by Kolbeck [4-7]. For dental applications, it has been concluded that $\Delta E=2.0$ is the maximum value of color difference acceptable for practical applications of the materials; however, several authors define this value as $\Delta E=3.3[5,8-10]$ or even $\Delta E=3.5$ or $3.7[6,11-13]$. It should be noted that the CIE Lab system may be used for describing foods, natural resources, pharmaceuticals, and dental materials. The study of color stability of dental materials includes several aspects, including: (i) the best material color match to the patient teeth $[9,14,15]$ and (ii) the influence of foods and drinks (coffee, tea, red wine, and juices) on the color $[6,7,12,13,16]$.

The aim of the study was to investigate the properties of six selected dental materials, chosen from the groups of composite and compomer materials, to obtain information on how selected staining liquids affect the color stability and reflectance of these materials. We hypothesized that there are differences between the staining potential of selected liquids on selected dental materials (hypothesis No. 1). Furthermore, we wanted to determine whether there is any difference in color change between selected composites and compomers. The null hypothesis was that there are no differences between the materials and that staining liquids do not affect color stability and reflectance of the dental materials chosen for the study.

\section{Materials and Methods}

Six dental materials were chosen for this study. Composite materials included: G-aenial (GC) (S1), Filtek $^{\mathrm{TM}}$ Z550 (3M) (S2), and Herculite XRV Ultra (Kerr) (S3); and compomers: Compoglass (Ivoclar Vivadent) (S4), Dyract ${ }^{\circledR}$ Extra (Dentsply) (S5), and Dyract ${ }^{\circledR}$ Flow (Dentsply) (S6).

G-aenial (GC) (S1) is a light-cured radiopaque hybrid composite restorative with a combination of two types of pre-polymerized resin fillers. They are produced by polymerizing a resin matrix in which micro-fillers were incorporated, and then milling the polymerized resin into particles averaging 16 to $17 \mu$ in size. The matrix consists of a mixture of urethane dimethacrylate (UDMA) and dimethacrylate co-monomers. G-aenial is bis-GMA free.

Filtek $^{\mathrm{TM}} \mathrm{Z} 550$ (3M) (S2) is a nano hybrid, visible-light activated, radiopaque, restorative composite. The filler is a combination of surface modified zirconia/silica and $20 \mathrm{~nm}$ surface modified silica particles. The inorganic filler loading is $81.8 \%$ by weight $(67.8 \%$ by volume), with the particle size of $20 \mathrm{~nm}$ for the silica and approximately 0.1-10 microns for the zirconia/silica. Filtek Z550 Nano Hybrid Universal Restorative contains BIS-GMA, UDMA, BISEMA, PEGDMA, and TEGDMA resins.

Herculite XRV Ultra (Kerr) (S3) is a nanohybrid composite material with an average filler particle size of 0.7 microns. 
Compoglass (Ivoclar Vivadent) (S4) is a light-curing, radiopaque compomer-based restorative material. The monomer matrix is composed of dimethacrylates. The particle size is between 0.2 and $3.0 \mu \mathrm{m}$.

Dyract Extra (Dentsply) (S5) is a universal light-cured compomer-based restorative material.

Dyract Flow (Dentsply) (S6) is a semi-fluid, light-cured compomer with acidic monomers important in the polymerization. The materials that were chosen for the study included composite resin and compomer-based materials that are widely used for aesthetic restoration of dental hard tissues [17]. The study was designed in such way in order to include materials that may be suitable for restoration in aesthetic zones in all clinical scenarios, including not only the need for perfect color match (which is the property of composite resin materials), but also the location of the defect (e.g., subgingival cavities that constitute an indication for compomers), and the strength of the planned restoration $[18,19]$.

Ten staining liquids were used, including distilled water, black tea, black tea with sugar, black coffee, black coffee with sugar, Coca-Cola ${ }^{\circledR}$, orange and currant juices, soy sauce, and wine. The staining was carried out at $37^{\circ} \mathrm{C}$, simulating the conditions in the human oral cavity. The measurements of color difference $(\Delta E)$ and the color parameters, including $\Delta a, \Delta b$, and $\Delta L$, were carried out using a Konica Minolta CM5 spetrocolorimeter at different staining times $(1,2,4,8,24,48,72$, and $168 \mathrm{~h})$. The resulting color change of the dental materials upon staining is presented as plots of $\Delta E$, diffuse-reflection spectra and Maxwell's triangle.

The tests of the dental materials S1-S6 were performed using the following liquids:

- $\quad$ Distilled water at $\mathrm{pH}=6.9$ for control.

- Tea: One bag of black tea (Lipton Tea) was added to $300 \mathrm{~mL}$ of distilled boiled water. After $5 \mathrm{~min}$ of infusion time, the liquid was filtered. The second solution was prepared in the same way with $10 \mathrm{~g}$ of sugar added. The $\mathrm{pH}$ was 4.8 and 4.7 for plain tea and tea with sugar, respectively.

- Coffee: $3.6 \mathrm{~g}$ of coffee (Nescafe ${ }^{\mathrm{TM}}$ ) were added to $300 \mathrm{~mL}$ of distilled and boiled water and infused for $10 \mathrm{~min}$; the liquid obtained was filtered through a paper filter. The second solution was prepared in the same way with $10 \mathrm{~g}$ of sugar added. The $\mathrm{pH}$ of coffee was 4.9 , independently of the presence of sugar.

- Commercially available bottled Coca-Cola ${ }^{\circledR}$ (a registered trademark) $(\mathrm{pH}=2.6)$, orange juice (Cappy, $\mathrm{pH}=4.0)$, currant juice (Cappy, $\mathrm{pH}=2.9$ ), soy sauce $(\mathrm{pH}=4.3)$, and red wine (Carlo Rossi, $\mathrm{pH}=3.2$ ) were all used without additional preparation.

Dental material specimens were placed in glass vials containing the staining liquids with their polished face up. The dish-shaped samples were made using a specially prepared transparent plastic mold. All samples were prepared in licensed dental laboratories strictly following the procedure and technological requirements. The surfaces of all samples were polished with fine-grain sand-paper PAP 201-1000. The diameter of the dish-shaped samples was $7 \mathrm{~mm}$ and they were $2 \mathrm{~mm}$ thick. The vials were stored at $37^{\circ} \mathrm{C}$. The color changes $(\Delta E)$ for all liquids and materials used were recorded after $1,2,4,8,24,48,72$, and $168 \mathrm{~h}$ of staining. After each staining interval, the samples were washed by immersing them five times in distilled water, dried with a paper towel, and subjected to color determination on the two main surfaces, and the color measurements of all samples were performed. After the measurements, all samples were returned to the staining vials, with the procedure repeated after each subsequent time interval.

Color and spectral reflectance at the baseline and after staining were measured on the CIE Lab color scale using the Konica Minolta CM-5 spectrocolorimeter (Tokyo, Japan). The CM-5 is a universal spectrophotometer used for measuring the color of solids (granulates, discs, pastes, and powders, including dental materials) and liquids (oils, beer). The measurements may be done in the reflectance mode, both on solid samples and on powders/pastes in Petri dishes, using different cell paths, and the aperture size of 3 to $30 \mathrm{~mm}$. The results are reported as spectral values, spectral graphs, colorimetric values, color-difference values, color-difference graphs, pass/fail judgment, pseudo-color, and color 
assessment. The spectral range is between 360 and $740 \mathrm{~nm}$, with a pulsed xenon lamp used as an excitation source.

The following scale was used to classify the resulting color difference values $(\Delta E)$ : the difference below 2.0 units in the CIE color space was classified as unnoticeable, between 2.1 and 3.5 units as slightly perceptible, between 3.6 and 5.0 units as clearly perceptible, and 5.1 units or over as pronounced.

\section{Results}

A summary of $\Delta E$ values at the end of the experiment is presented in Figure 1. $\Delta L$ values throughout the whole immersion process in all liquids for all materials are provided in Figures 2-11, and they show an overall trend for each staining liquid.

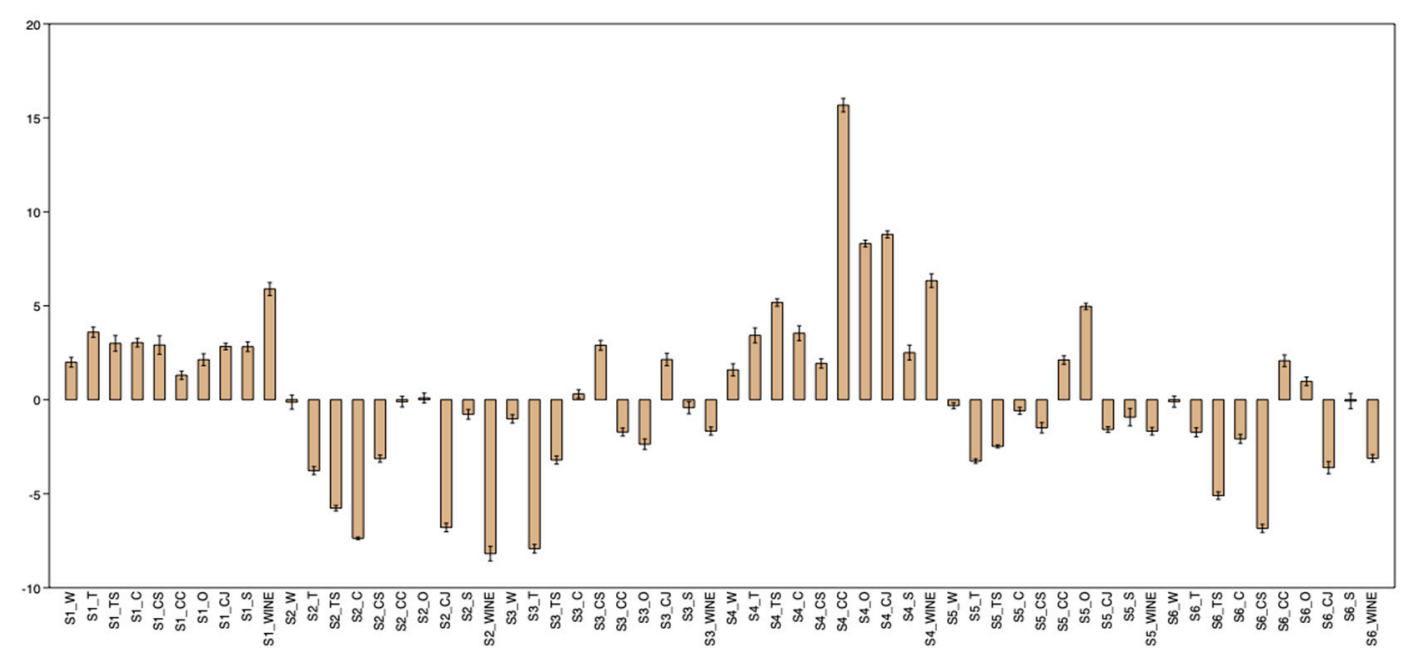

Figure 1. $\Delta E$ values at the end of the experiment for all staining liquids. Suffixes denote the liquid (W-water, T-tea, TS—-tea with sugar, C-coffee, CS—coffee with sugar, CC-Coca-Cola ${ }^{\circledR}, \mathrm{O}$-orange juice, CJ-currant juice, S-soy sauce, WINE-wine).

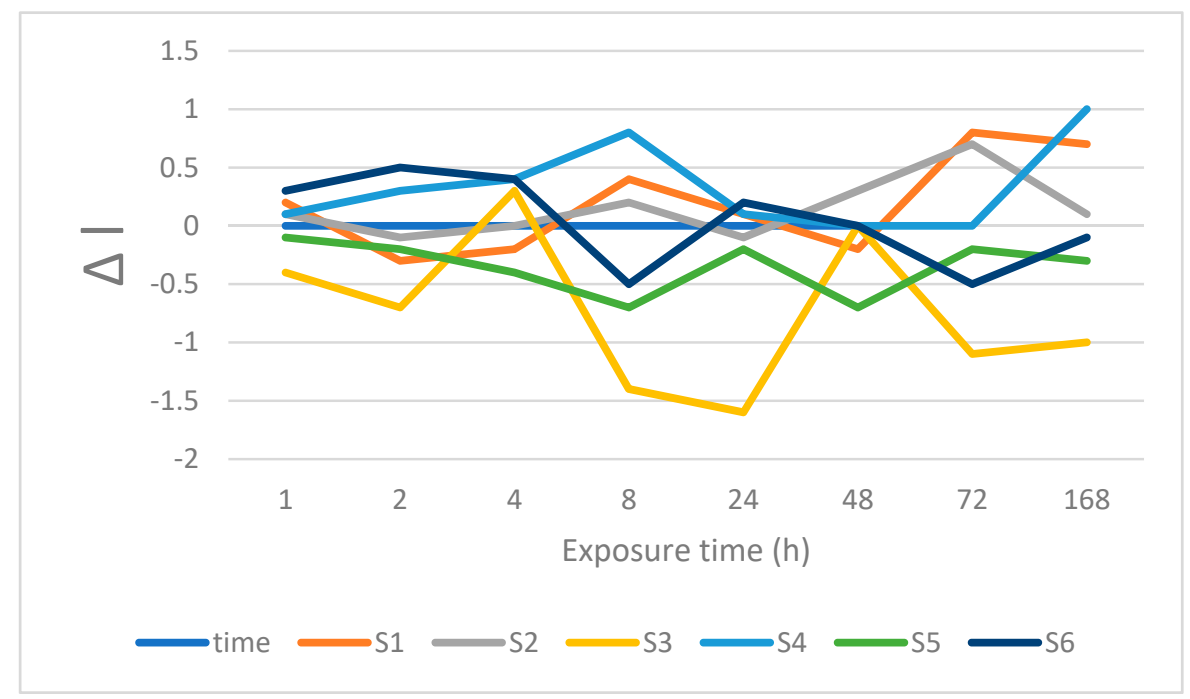

Figure 2. Changes is lightness after immersion in water. 


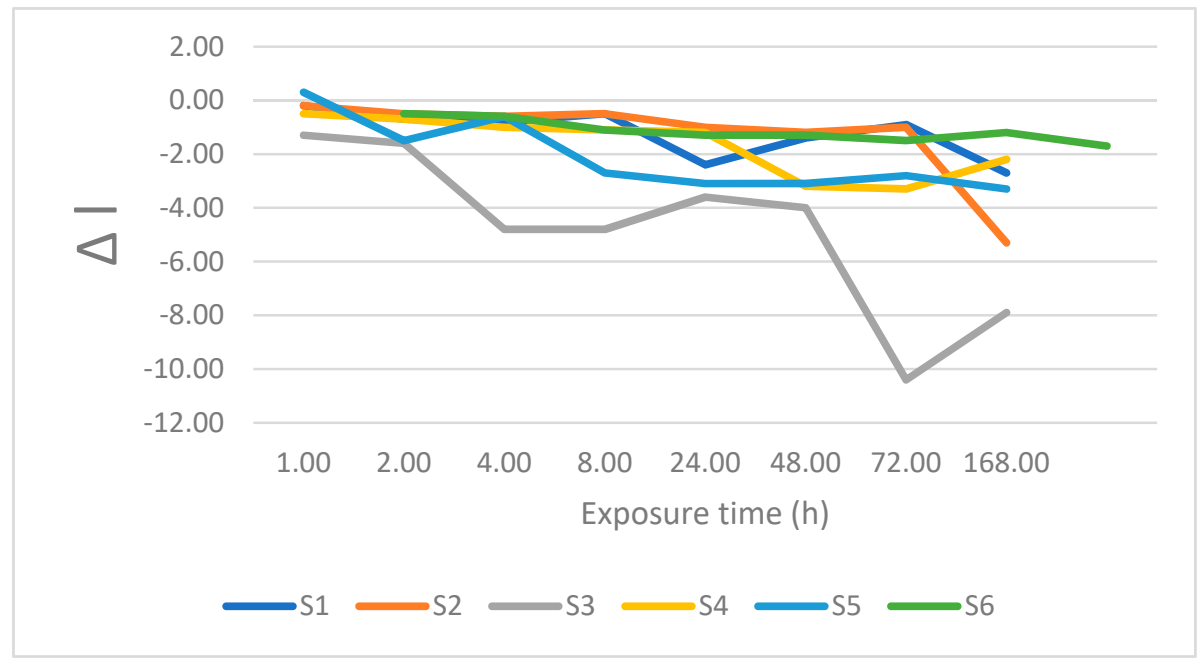

Figure 3. Changes is lightness after immersion in tea.

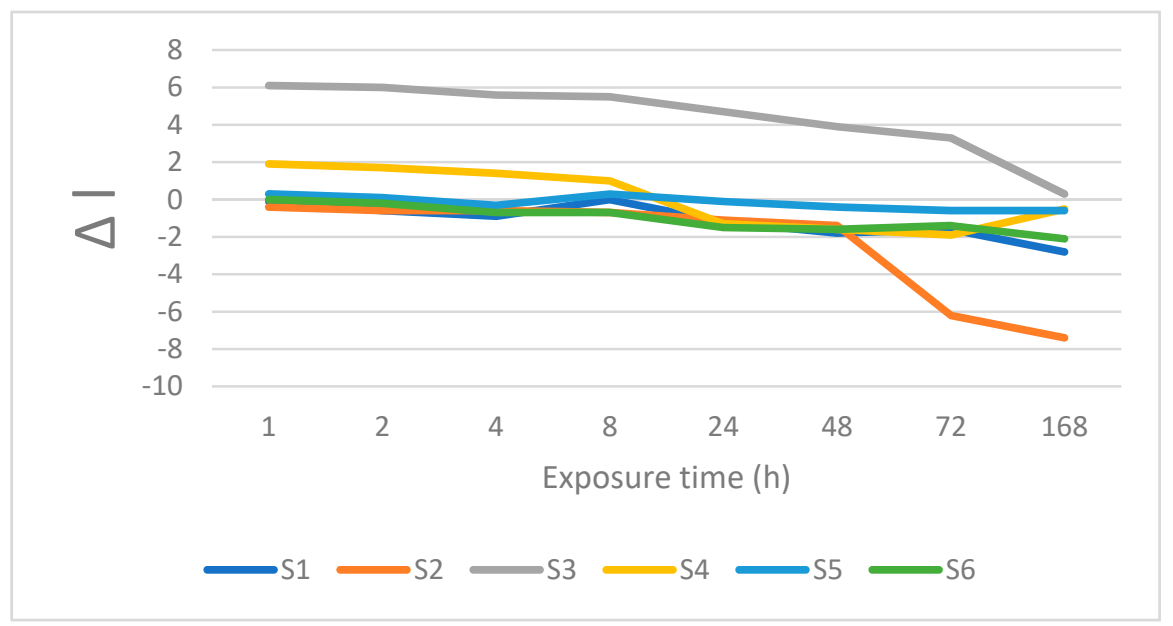

Figure 4. Changes is lightness after immersion in coffee.

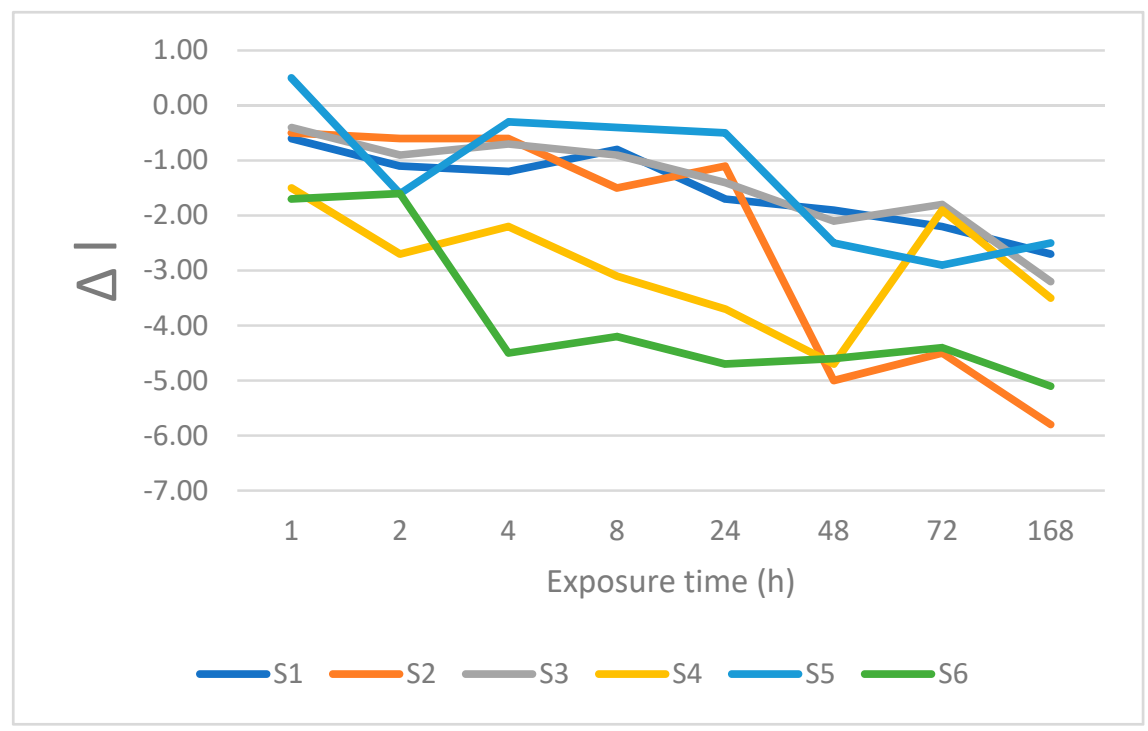

Figure 5. Changes is lightness after immersion in sweetened tea. 


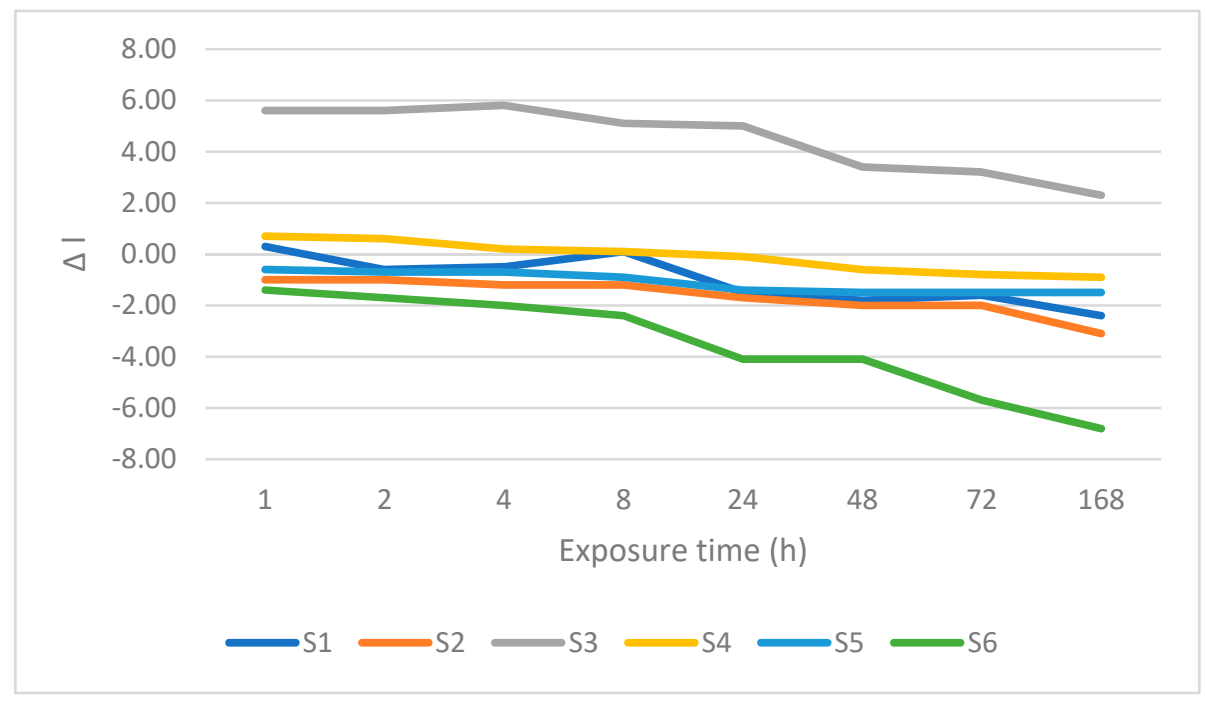

Figure 6. Changes is lightness after immersion in sweetened coffee.

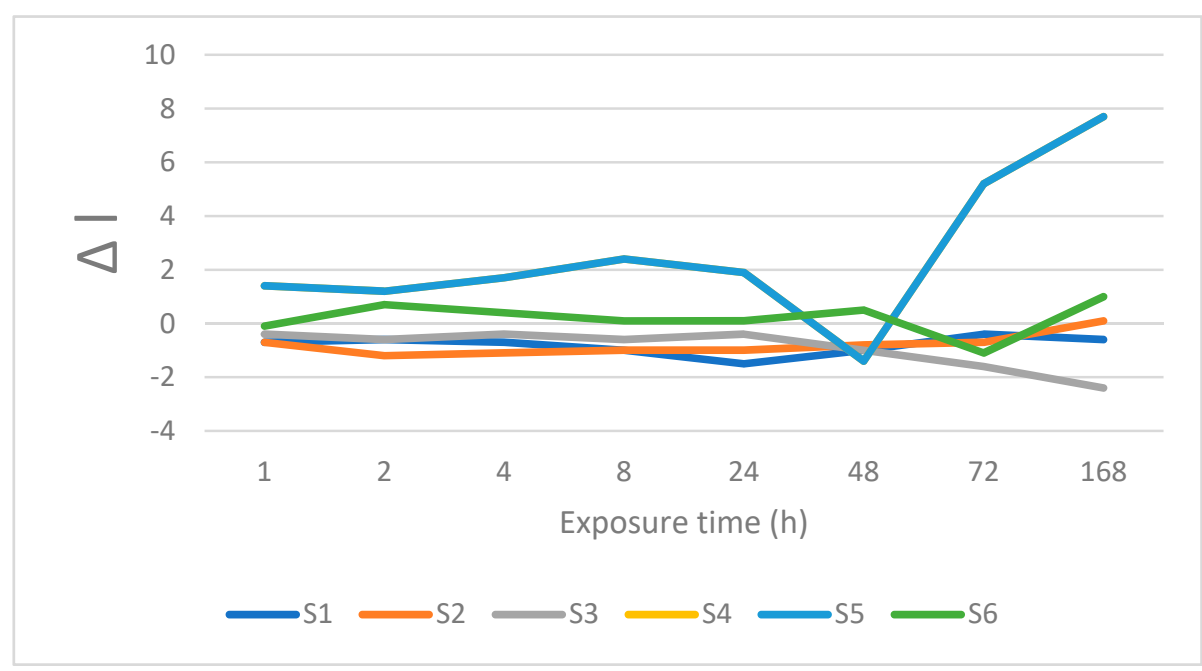

Figure 7. Changes is lightness after immersion in orange juice.

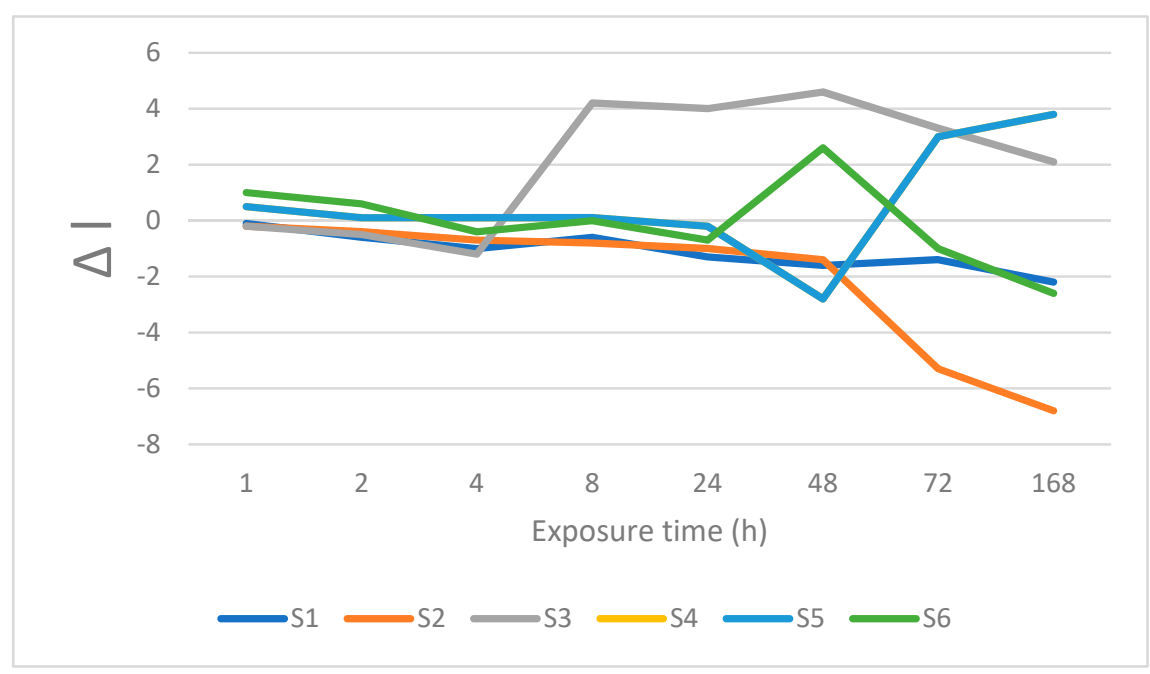

Figure 8. Changes is lightness after immersion in currant juice. 


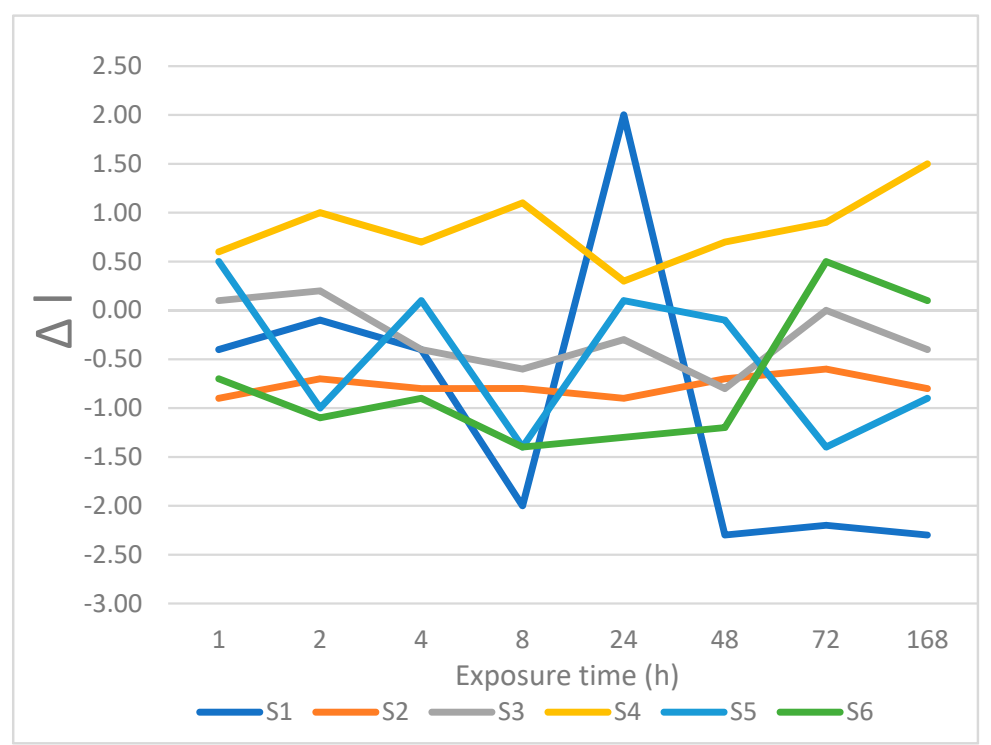

Figure 9. Changes is lightness after immersion in soy sauce.

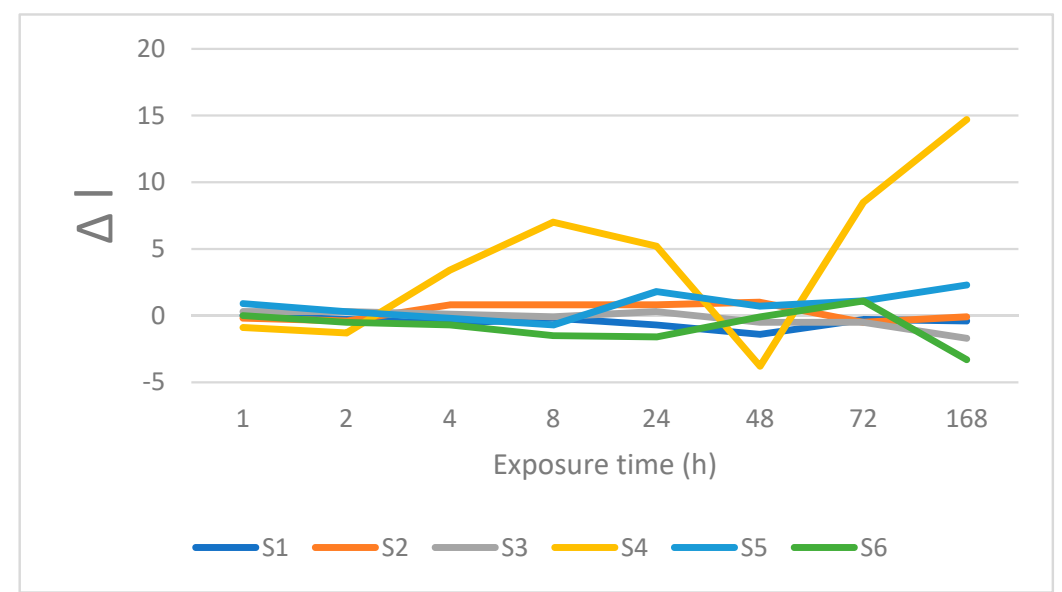

Figure 10. Changes is lightness after immersion in Coca-Cola ${ }^{\circledR}$.

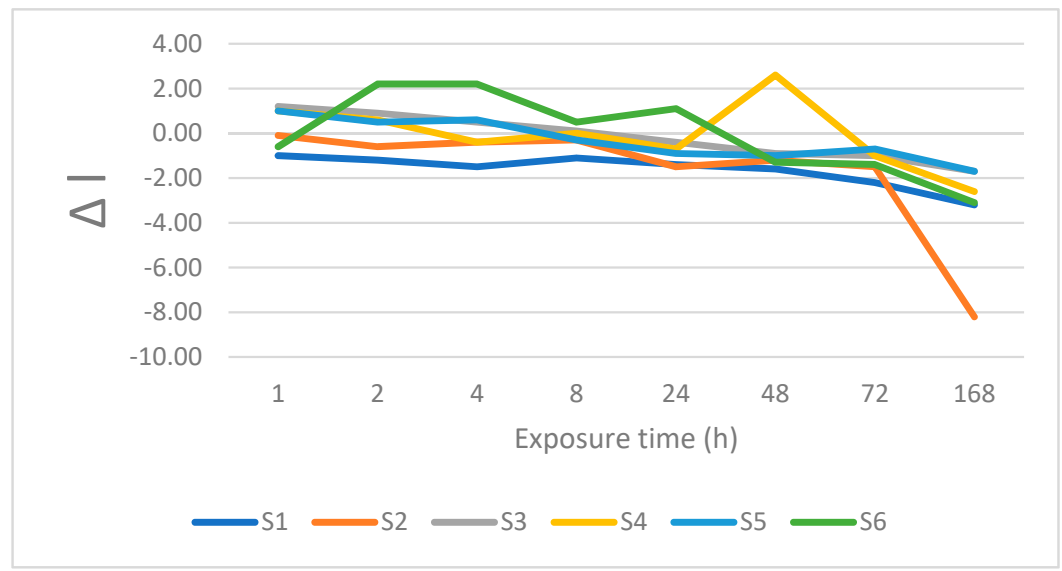

Figure 11. Changes is lightness after immersion in wine.

Statistical analysis was performed with the use of Kruskal-Wallis ANOVA, with significance level set at 0.05 . In order to determine statistical significance, $\Delta E$ values were compared for all staining 
liquids and all materials. The results are presented in Tables 1-10 below. A narrative description of the most important findings is presented in Sections 3.1-3.6.

Table 1. Differences in $\Delta E$ after $168 \mathrm{~h}$ immersion in water.

\begin{tabular}{ccccccc}
\hline Materials & S1 & S2 & S3 & S4 & S5 & S6 \\
\hline S1 & - & $p<0.001^{*}$ & $p<0.001^{*}$ & 0.3253 & $p<0.001^{*}$ & $p<0.001^{*}$ \\
S2 & $p<0.001^{*}$ & - & $0.02608^{*}$ & $p<0.001^{*}$ & 0.3408 & 0.8226 \\
S3 & $p<0.001^{*}$ & $0.02608^{*}$ & - & $p<0.001^{*}$ & 0.2033 & $0.04542^{*}$ \\
S4 & 0.3253 & $0.001234^{*}$ & $p<0.001^{*}$ & - & $p<0.001^{*}$ & $0.00055^{*}$ \\
S5 & $p<0.001^{*}$ & 0.3408 & 0.2033 & $p<0.001^{*}$ & - & 0.4663 \\
S6 & $p<0.001^{*}$ & 0.8226 & $0.04542^{*}$ & $0.00055^{*}$ & 0.4663 & - \\
\hline
\end{tabular}

${ }^{*}$ Denotes a statistically significant difference (Kruskal-Wallis ANOVA, Dunn's post-test).

Table 2. Differences in $\Delta E$ after $168 \mathrm{~h}$ immersion in tea.

\begin{tabular}{ccccccc}
\hline Materials & S1 & S2 & S3 & S4 & S5 & S6 \\
\hline S1 & - & $p<0.001^{*}$ & $p<0.001^{*}$ & 0.9447 & $p<0.001^{*}$ & $p<0.001^{*}$ \\
S2 & $p<0.001^{*}$ & - & $0.0007099^{*}$ & $p<0.001^{*}$ & 0.6011 & $0.006398^{*}$ \\
S3 & $p<0.001^{*}$ & $0.0007099^{*}$ & - & $p<0.001^{*}$ & $p<0.001^{*}$ & $p<0.001^{*}$ \\
S4 & 0.9447 & $p<0.001^{*}$ & $p<0.001^{*}$ & - & $p<0.001^{*}$ & $0.0001174^{*}$ \\
S5 & $p<0.001^{*}$ & $0.6011^{*}$ & $p<0.001^{*}$ & $p<0.001^{*}$ & - & 0.02753 \\
S6 & $p<0.001^{*}$ & $0.006398^{*}$ & $p<0.001^{*}$ & $0.0001174^{*}$ & $0.02753^{*}$ & - \\
\hline
\end{tabular}

${ }^{*}$ Denotes a statistically significant difference (Kruskal-Wallis ANOVA, Dunn's post-test).

Table 3. Differences in $\Delta E$ after $168 \mathrm{~h}$ immersion in water.

\begin{tabular}{ccccccc}
\hline Materials & S1 & S2 & S3 & S4 & S5 & S6 \\
\hline S1 & - & $p<0.001^{*}$ & $p<0.001^{*}$ & 0.1472 & $0.001256^{*}$ & $p<0.001^{*}$ \\
S2 & $p<0.001^{*}$ & - & $p<0.001^{*}$ & $p<0.001^{*}$ & $p<0.001^{*}$ & 0.2762 \\
S3 & $p<0.001^{*}$ & $p<0.001^{*}$ & - & $p<0.001^{*}$ & 0.1703 & $0.004364^{*}$ \\
S4 & 0.1472 & $p<0.001^{*}$ & $p<0.001^{*}$ & - & $p<0.001^{*}$ & $p<0.001^{*}$ \\
S5 & $0.001256^{*}$ & $p<0.001^{*}$ & 0.1703 & $p<0.001^{*}$ & - & $p<0.001^{*}$ \\
S6 & $p<0.001^{*}$ & 0.2762 & $0.004364^{*}$ & $p<0.001^{*}$ & $p<0.001^{*}$ & - \\
\hline
\end{tabular}

${ }^{*}$ Denotes a statistically significant difference (Kruskal-Wallis ANOVA, Dunn's post-test).

Table 4. Differences in $\Delta E$ after $168 \mathrm{~h}$ immersion in coffee.

\begin{tabular}{ccccccc}
\hline Materials & S1 & S2 & S3 & S4 & S5 & S6 \\
\hline S1 & - & $p<0.001^{*}$ & $0.000736^{*}$ & 0.8332 & $p<0.001^{*}$ & $p<0.001^{*}$ \\
S2 & $p<0.001^{*}$ & - & $p<0.001^{*}$ & $p<0.001^{*}$ & $p<0.001^{*}$ & $0.00479^{*}$ \\
S3 & $0.000736^{*}$ & $p<0.001^{*}$ & - & 0.0003352 & 0.1421 & $0.0005351^{*}$ \\
S4 & 0.8332 & $p<0.001^{*}$ & $0.0003352^{*}$ & - & $p<0.001 *$ & $p<0.001^{*}$ \\
S5 & $p<0.001^{*}$ & $p<0.001^{*}$ & 0.1421 & $p<0.001^{*}$ & - & 0.0461 \\
S6 & $p<0.001^{*}$ & $0.00479^{*}$ & $0.0005351^{*}$ & $p<0.001^{*}$ & $0.0461 *$ & - \\
\hline
\end{tabular}

${ }^{*}$ Denotes a statistically significant difference (Kruskal-Wallis ANOVA, Dunn's post-test).

Table 5. Differences in $\Delta E$ after $168 \mathrm{~h}$ immersion in coffee with sugar.

\begin{tabular}{ccccccc}
\hline Materials & S1 & S2 & S3 & S4 & S5 & S6 \\
\hline S1 & - & $p<0.001^{*}$ & 0.7738 & 0.4207 & $p<0.001^{*}$ & $p<0.001^{*}$ \\
S2 & $p<0.001^{*}$ & - & $p<0.001^{*}$ & $p<0.001^{*}$ & $0.08133^{*}$ & $0.008918^{*}$ \\
S3 & 0.7738 & $p<0.001^{*}$ & - & 0.2745 & $p<0.001^{*}$ & $p<0.001^{*}$ \\
S4 & 0.4207 & $p<0.001^{*}$ & 0.2745 & - & $0.0001393^{*}$ & $p<0.001^{*}$ \\
S5 & $p<0.001^{*}$ & 0.08133 & $p<0.001^{*}$ & $0.0001393^{*}$ & - & $p<0.001^{*}$ \\
S6 & $p<0.001^{*}$ & $0.008918^{*}$ & $p<0.001^{*}$ & $p<0.001^{*}$ & $p<0.001 *$ & - \\
\hline
\end{tabular}

${ }^{*}$ Denotes a statistically significant difference (Kruskal-Wallis ANOVA, Dunn's post-test). 
Table 6. Differences in $\Delta E$ after $168 \mathrm{~h}$ immersion in Coca-Cola ${ }^{\circledR}$.

\begin{tabular}{ccccccc}
\hline Materials & S1 & S2 & S3 & S4 & S5 & S6 \\
\hline S1 & - & $0.01603^{*}$ & $p<0.001^{*}$ & $p<0.001^{*}$ & 0.1801 & 0.2334 \\
S2 & $0.01603^{*}$ & - & 0.0222 & $p<0.001^{*}$ & $0.0001777^{*}$ & $0.0003182^{*}$ \\
S3 & $p<0.001^{*}$ & $0.0222^{*}$ & - & $p<0.001^{*}$ & $p<0.001^{*}$ & $p<0.001^{*}$ \\
S4 & $p<0.001^{*}$ & $p<0.001^{*}$ & $p<0.001^{*}$ & - & $p<0.001^{*}$ & $p<0.001^{*}$ \\
S5 & 0.1801 & $0.0001777^{*}$ & $p<0.001^{*}$ & $p<0.001^{*}$ & - & 0.8818 \\
S6 & 0.2334 & $0.0003182^{*}$ & $p<.0 .001^{*}$ & $p<0.001^{*}$ & 0.8818 & - \\
\hline
\end{tabular}

* Denotes a statistically significant difference (Kruskal-Wallis ANOVA, Dunn's post-test).

Table 7. Differences in $\Delta E$ after $168 \mathrm{~h}$ immersion in orange juice.

\begin{tabular}{ccccccc}
\hline Materials & S1 & S2 & S3 & S4 & S5 & S6 \\
\hline S1 & - & $0.007263^{*}$ & $p<0.001^{*}$ & $p<0.001^{*}$ & $0.002424^{*}$ & 0.1553 \\
S2 & $0.007263^{*}$ & - & 0.009247 & $p<0.001^{*}$ & $p<0.001^{*}$ & 0.2064 \\
S3 & $p<0.001^{*}$ & $0.009247^{*}$ & - & $p<0.001^{*}$ & $p<0.001^{*}$ & $0.0001105^{*}$ \\
S4 & $p<0.001^{*}$ & $p<.0 .001^{*}$ & $p<0.001^{*}$ & - & 0.0175 & $p<0.001^{*}$ \\
S5 & $0.002424^{*}$ & $p<.0 .001^{*}$ & $p<0.001^{*} 7$ & 0.0175 & - & $p<0.001^{*}$ \\
S6 & 0.1553 & 0.2064 & $0.0001105^{*}$ & $p<0.001^{*}$ & $p<0.001^{*}$ & - \\
\hline
\end{tabular}

${ }^{*}$ Denotes a statistically significant difference (Kruskal-Wallis ANOVA, Dunn's post-test).

Table 8. Differences in $\Delta E$ after $168 \mathrm{~h}$ immersion in currant juice.

\begin{tabular}{ccccccc}
\hline Materials & S1 & S2 & S3 & S4 & S5 & S6 \\
\hline S1 & - & $p<0.001^{*}$ & 0.5267 & $0.002288^{*}$ & $p<0.001^{*}$ & $p<0.001^{*}$ \\
S2 & $p<0.001^{*}$ & - & $p<0.001^{*}$ & $p<0.001^{*}$ & $p<0.001^{*}$ & $0.02012^{*}$ \\
S3 & 0.5267 & $p<0.001^{*}$ & - & $0.0002305^{*}$ & $0.0008532^{*}$ & $p<0.001^{*}$ \\
S4 & $0.002288^{*}$ & $p<0.001^{*}$ & $0.0002305^{*}$ & - & $p<0.001^{*}$ & $p<0.001^{*}$ \\
S5 & $p<0.001^{*}$ & $p<0.001^{*}$ & $0.0008532^{*}$ & $p<0.001^{*}$ & - & 0.09518 \\
S6 & $p<0.001^{*}$ & $0.02012^{*}$ & $p<0.001^{*}$ & $p<0.001^{*}$ & 0.09518 & - \\
\hline
\end{tabular}

${ }^{*}$ Denotes a statistically significant difference (Kruskal-Wallis ANOVA, Dunn's post-test).

Table 9. Differences in $\Delta E$ after $168 \mathrm{~h}$ immersion in soy sauce.

\begin{tabular}{ccccccc}
\hline Materials & S1 & S2 & S3 & S4 & S5 & S6 \\
\hline S1 & - & $p<0.001^{*}$ & $p<0.001^{*}$ & 0.356 & $p<0.001^{*}$ & $p<0.001^{*}$ \\
S2 & $p<0.001^{*}$ & - & 0.5504 & $p<0.001^{*}$ & 0.8926 & 0.1891 \\
S3 & $p<0.001^{*}$ & 0.5504 & - & $p<0.001^{*}$ & 0.644 & 0.474 \\
S4 & 0.356 & $p<0.001^{*}$ & $p<0.001^{*}$ & - & $p<0.001^{*}$ & 0.000176 \\
S5 & $p<0.001^{*}$ & 0.8926 & 0.644 & $p<0.001^{*}$ & - & 0.2387 \\
S6 & $p<0.001^{*}$ & 0.1891 & 0.474 & $0.000176^{*}$ & 0.2387 & - \\
\hline
\end{tabular}

* Denotes a statistically significant difference (Kruskal-Wallis ANOVA, Dunn's post-test).

Table 10. Differences in $\Delta E$ after $168 \mathrm{~h}$ immersion in soy sauce.

\begin{tabular}{ccccccc}
\hline Materials & S1 & S2 & S3 & S4 & S5 & S6 \\
\hline S1 & - & $p<0.001^{*}$ & $p<0.001^{*}$ & 0.8313 & $p<0.001^{*}$ & $p<0.001^{*}$ \\
S2 & $p<0.001^{*}$ & - & $p<0.001^{*}$ & $p<0.001^{*}$ & $p<0.001^{*}$ & 0.003614 \\
S3 & $p<0.001^{*}$ & $p<0.001^{*}$ & - & $p<0.001^{*}$ & 0.9891 & $0.02951^{*}$ \\
S4 & $0.8313^{*}$ & $p<0.001^{*}$ & $p<0.001^{*}$ & - & $p<0.001^{*}$ & $p<0.001^{*}$ \\
S5 & $p<0.001^{*}$ & $p<0.001^{*}$ & 0.9891 & $p<0.001^{*}$ & - & 0.02851 \\
S6 & $p<0.001^{*}$ & $0.003614^{*}$ & $0.02951^{*}$ & $p<0.001^{*}$ & $0.02851^{*}$ & - \\
\hline
\end{tabular}

* Denotes a statistically significant difference (Kruskal-Wallis ANOVA, Dunn's post-test). 


\subsection{Material S1}

For Material S1, clearly perceptible differences with $\Delta E$ between 3.6 and 5.0 were recorded for tea, and tea with sugar. Imperceptible differences $(\Delta E<2)$ were noted after immersion in water and Coca-Cola ${ }^{\circledR}$. Slightly perceptible differences with $\Delta E$ between 2.1 and 3.5 were recorded for coffee, coffee with sugar, soy sauce, orange juice, and currant juice.

The majority of the staining liquids produced positive changes in $\Delta a$ after $168 \mathrm{~h}$ of immersion, with the highest values observed tea, tea with sugar, and wine $(\Delta a=1.0)$. Low negative values of $\Delta a$ were recorded after immersion in soy sauce, orange juice, and currant juice. The color difference $\Delta b$ was positive for all staining liquids, with the highest value obtained for wine $(\Delta b=4.9)$. For most liquids, $\Delta b$ increased monotonously, with the highest value achieved after $168 \mathrm{~h}$.

The lightness value was universally lower after $168 \mathrm{~h}$, with $\Delta L$ always negative, with the exception of distilled water. Concluding, after $168 \mathrm{~h}$ immersion of S1 in most of the staining liquids, the contributions of red and yellow became more pronounced than those of green and blue, respectively. The lightness decreased after immersion in almost every staining liquid.

\subsection{Material S2}

Pronounced differences with the $\Delta E>5.1$ were recorded for tea, tea with sugar, coffee, currant juice, and wine. The highest value of $\Delta \mathrm{E}$ was recorded in tea with sugar as the staining liquid $(\Delta E=16.1)$. At the same time, water, $\mathrm{Coca}-\mathrm{Cola}{ }^{\circledR}$, orange juice, and soy sauce produced imperceptible color change, with $\Delta E$ below 2 .

The highest negative $\Delta a$ value was obtained after $168 \mathrm{~h}$ immersion into tea with sugar $(\Delta a=-3.3)$. A significant negative value $(\Delta a=-1.0)$ was obtained in currant juice. Rather small negative $\Delta a$ values were obtained for orange juice and soy sauce. At the same time, the highest positive $\Delta a$ values were recorded for coffee $(\Delta a=1.9)$ and wine $(\Delta a=1.1)$. Rather small positive values after $168 \mathrm{~h}$ immersion of S2 we obtained for water, tea, coffee with sugar, and Coca-Cola ${ }^{\circledR}$. The $\Delta b$ values were always positive, with the highest obtained for tea, tea with sugar, coffee, and wine, and the lowest for water, coffee with sugar, Coca-Cola ${ }^{\circledR}$, orange juice, and currant juice. Soy sauce produced negative intermediate values of $\Delta b$ ( -0.9 after $4 \mathrm{~h})$, with the final value $\Delta b=0$ after $168 \mathrm{~h}$.

A reduction in lightness (negative $\Delta \mathrm{L}$ ) was recorded for every staining liquid, with the exception of water ( $\Delta L=1.1$ after $168 \mathrm{~h}$ ) and orange juice. The most significant changes in lightness were recorded for tea, tea with sugar, coffee, coffee with sugar, currant juice, and wine. For most of the staining liquids, the lightness was changing monotonously in time. This material became greener in tea with sugar, currant juice, orange juice, and soy sauce, while coffee, wine, water, tea, coffee with sugar, and Coca-Cola ${ }^{\circledR}$ made it redder. Additionally, tea, tea with sugar, coffee and wine made it yellower. This material became darker in every staining liquid.

\subsection{Material S3}

This composite material produced distinct discoloration after $168 \mathrm{~h}$ immersion in each of the staining liquids. The largest $\Delta E$ value was recorded for tea and coffee, $\Delta E=14.7$ and 8.9 , respectively. Interestingly, added sugar reduced $\Delta E$ ( 5.1 for tea with sugar and 6.2 for coffee with sugar). A relatively large $\Delta E$ value was recorded for wine ( $\Delta E=8.2$ after $168 \mathrm{~h}$ ). The lowest values of $\Delta E$ were obtained in water and in Coca-Cola ${ }^{\circledR}-2.0$ and 3.0, respectively. Water was the only liquid that produced $\Delta E$ below 2 with imperceptible differences after $168 \mathrm{~h}$. Three staining liquids, including orange juice, currant juice, and soy sauce, produced $\Delta E$ between 3.6 and 5.0, with clearly perceptible differences.

Most staining liquids produced positive values of $\Delta a$ after $168 \mathrm{~h}$ immersion, including the highest value for tea. Small negative $\Delta a$ values were obtained for four staining liquids, including coffee with sugar, currant juice, soy sauce, and wine. Generally, red color contributed more than green color for this material. The $\Delta b$ values after $168 \mathrm{~h}$ were always positive, independently on the staining liquid. The most significant changes were recorded for tea (11.3), coffee (8.9), wine (7.9), and coffee with sugar 
(5.5). Generally, contribution of yellow color increased at the cost of the blue color (negative values of $\Delta b$ ).

The largest change in lightness $(\Delta L)$ was obtained for tea. Generally, most staining liquids produced negative $\Delta L$ values. Low positive $\Delta L$ values were obtained for coffee (0.3), coffee with sugar (2.9), and currant juice (2.1).

\subsection{Material S4}

Tea with sugar, Coca-Cola ${ }^{\circledR}$, orange juice, currant juice, and wine caused pronounced color differences $(\Delta E>5.1)$ after $168 \mathrm{~h}$. Pronounced color differences already appear for tea with sugar after $1 \mathrm{~h}$ immersion, remaining almost unchanged at later times. Higher $\Delta E$ values were obtained for Coca-Cola ${ }^{\circledR}$. In the beginning, the color changes were imperceptible $(\Delta E=1.2$ after $1 \mathrm{~h}$ and 1.6 after $2 \mathrm{~h}$ ); however, they increased to 5.3 after $4 \mathrm{~h}$. The values recorded at later times all correspond to pronounced color differences. Orange juice produced monotonous growth of $\Delta E$, starting from $2.4(4 \mathrm{~h})$ to $8.3(168 \mathrm{~h})$. Moreover, the initial changes ( 1 and $2 \mathrm{~h}$ ) were relatively low, 1.5 and 1.8 , respectively. The $\Delta E$ parameter was increasing for wine, with pronounced color differences after $168 \mathrm{~h}, \Delta E=6.3$. At the same time, distilled water, coffee with sugar, and soy sauce produced only imperceptible or slightly perceptible color differences. In addition, coffee and tea caused slightly perceptible color differences throughout the entire staining period.

The staining liquids form two distinct groups, when it comes to $\Delta a$. The first group (distilled water, tea, tea with sugar, soy sauce, Coca-Cola ${ }^{\circledR}$, currant juice, and wine) produced positive $\Delta a$ values, whereas coffee, coffee with sugar, and orange juice produced negative $\Delta a$, values. Moreover, the positive values were typically higher than negative-for example, after $168 \mathrm{~h}$ immersion, $\Delta a=3.8$ (currant juice) and $\Delta a=-0.5$ (coffee with sugar). Positive changes for $\Delta b$ were recorded for distilled water, tea, tea with sugar, coffee, soy sauce, and coffee with sugar after $168 \mathrm{~h}$ immersion. At the same time, negative $\Delta b$ values were recorded for Coca-Cola ${ }^{\circledR}$, orange juice, currant juice, and wine.

Distilled water, soy sauce, Coca-Cola ${ }^{\circledR}$, orange juice, and currant juice caused positive $\Delta L$ values, with negative values recorded for tea, tea with sugar, coffee, coffee with sugar, and wine. Note that monotonous decrease in lightness was recorded for tea and tea with sugar during the entire experiment. Added sugar in tea and coffee caused a small reduction in lightness.

\subsection{Material S5}

Water was the only liquid that did not cause perceptible color changes, with the strongest changes recorded for wine. Wine did not cause any perceptible changes up to $8 \mathrm{~h}(\Delta E<2)$, with the changes becoming slightly perceptible at $24 \mathrm{~h}(\Delta E=2.3)$ and pronounced starting from $48 \mathrm{~h}(\Delta E>5.1)$. Slightly perceptible color differences by the end of the experiment were recorded for coffee, Coca-Cola ${ }^{\circledR}$, and soy sauce. Clearly perceptible color differences were recorded for tea, tea with sugar, coffee with sugar, orange juice, and currant juice. Interestingly, coffee with sugar and orange juice produced $\Delta E>2$ right from the beginning of the experiment. Additionally, currant juice caused clearly perceptible differences already at $4 \mathrm{~h}$, which remained almost unchanged until the end of the measurements.

The values of $\Delta a$ were positive by the end of the experiment, with the exception of wine, staying rather small-for example, 0.6 in currant juice and distilled water. At the same time, we recorded $\Delta a=-4.1$ for wine. Wine enhanced the green color contribution, whereas all the other staining liquids enhanced the red color contribution. With the exception of the distilled water $(\Delta b=-0.3$ after $168 \mathrm{~h}$ immersion), the values by the end of the experiment are positive with the highest $\Delta b=17.9$ for wine. Therefore, every staining liquid enhanced the contribution of the yellow color.

Most of the staining liquids caused negative $\Delta L$ values, including distilled water, tea, tea with sugar, coffee, coffee with sugar, currant juice, soy sauce, and wine, with positive values recorded only for Coca-Cola ${ }^{\circledR}$ and orange juice. 


\subsection{Material S6}

Pronounced color differences by the end of the experiment $(\Delta E>5.1)$ were recorded for tea with sugar, coffee with sugar, currant juice, and soy sauce. Coffee with sugar produced only imperceptible differences of color from 1 to $4 \mathrm{~h}$ with $\Delta E<2$. The value at $8 \mathrm{~h}$ corresponds to slightly perceptible color difference with $\Delta E=2.4$. Clearly perceptible color differences for coffee with sugar were recorded after $24 \mathrm{~h}$, with $\Delta E=4.7$. Pronounced color differences were obtained between 48 and $168 \mathrm{~h}(\Delta E=10.0$ in $168 \mathrm{~h}$ ). Some staining liquids caused smaller color changes after $168 \mathrm{~h}$, including coffee, orange juice, and wine, with $\Delta E$ between 3.6 and 5.0, corresponding to clearly perceptible color differences. Slightly perceptible color differences after $168 \mathrm{~h}$ were recorded for tea and Coca-Cola ${ }^{\circledR}$. Only distilled water by the end of the experiment caused imperceptible color differences.

Four of the staining liquids, including tea, Coca-Cola ${ }^{\circledR}$, currant juice, and wine produced positive values of $\Delta a$, corresponding to an increased contribution of red color. The values of $\Delta a$ by the end of the experiment vary between staining liquids-for example, 3.0 for currant juice but only 0.2 for tea. Two of the staining liquids caused no changes by the end of the experiment (distilled water and coffee with sugar, $\Delta E=0$ ). However, green color contribution increased for tea with sugar, coffee, orange juice, and soy sauce, with the highest value for soy sauce, $\Delta a=-3.2$ and the lowest for coffee and tea with sugar $(-0.5)$. The contribution of yellow and blue colors is expressed by the value of $\Delta b$. Positive $\Delta b$ values correspond to increased yellow color contribution, while negative values correspond to increased blue color contribution. Positive values of $\Delta b$ were recorded for tea, tea with sugar, coffee, coffee with sugar, orange juice, and soy sauce. The highest value of $\Delta b$ by the end of the experiment was 10.7 (soy sauce) and the lowest 2.3 (tea). The negative values of $\Delta b$ were less pronounced, varying from -0.8 for wine to -0.2 for distilled water.

Negative lightness changes were recorded for most staining liquids by the end of the experiment, except for Coca-Cola ${ }^{\circledR}$, orange juice, and soy sauce that produced positive $\Delta L$ values.

\subsection{Discussion}

The measurements were performed on three dental composites (S1: G-aenial (GC), S2: Filtek ${ }^{\mathrm{TM}}$ Z550 (GC), and S3: Herculite XRV Ultra) and three dental compomers (S4: Compoglass (Invoclar Vivadent), S5: Dyract ${ }^{\circledR}$ Extra (Dentsply), and S6: Dyract ${ }^{\circledR}$ Flow (Dentsply)) before and after immersion into staining liquids, including distilled water, tea, tea with sugar, coffee, coffee with sugar, Coca-Cola $($, orange juice, currant juice, soy sauce, and wine. The selection of products included commercially available liquids, most of which were used in other studies $[12,20]$ We measured color differences, as characterized by $\Delta E$, using a Konica Minolta CM-5 spectrocolorimeter after 1, 2, 4, 8, 24, 48, 72, and $168 \mathrm{~h}$ of immersion. Additionally, we measured the color parameters, including $\Delta a, \Delta b$, and $\Delta L$ for all of the examined dental materials and staining liquids. The color changes varied in function of the dental material and staining liquid. Most of the dental materials suffered significant changes in lightness $(\Delta L)$ along with changes in the total color, with the samples generally becoming darker. Moreover, the samples generally became more yellow due to changes in the $\Delta a$ color parameter.

Discoloration of dental restorative materials constitutes a significant challenge in modern dentistry whose aim is to recreate dental morphology in a repeatable and stable manner [21]. Unfortunately, we found that most of the dental materials changed their color from light cream to yellowish or light-brown after exposure to selected staining liquids. Therefore, the null hypothesis was rejected.

In our study, among composites, the weakest total color change was recorded for S1. Generally, only wine after $168 \mathrm{~h}$ caused pronounced color difference, with slight or clearly perceptible color differences for the majority of the staining liquids. This is similar to the observation made by Falkensammer et al. who also observed that red wine possesses mostly pronounced discoloration potential [22]. Composites S2 and S3 had a lower resistance in terms of the total color change. Both these composites suffered pronounced color change after $168 \mathrm{~h}$ for five staining liquids, including wine, coffee, and tea. Imperceptible color differences were recorded for four immersion liquids (material S2) and only in distilled water (material S3) by the end of the experiment, while other staining liquids 
caused clearly or slightly perceptible color differences. This can be attributed both to intrinsic colorants present in foods, but also to the internal structure of the material and to its surface properties. When it comes to the composition of the materials, both the size of particles and the type of the resin may influence it, as it is generally accepted that higher water sorption results in higher discoloration rate [23] Nanofiller composites absorb the dyes easier than microhybrids. Research studies show that acidic drinks, e.g., Coca-Cola ${ }^{\circledR}$, increase surface roughness, which causes the specimens to absorb extrinsic substances to a higher extent [24]. One cannot omit the issue of surface polishing and preparation, which, when performed correctly, may also affect the discoloration rate [25-27]. Additionally, $\mathrm{pH}$ within the oral cavity and the food may influence the whole discoloration process; it is generally accepted that the lower the $\mathrm{pH}$ value, the quicker the process [28]. This may be a factor that limits the change in color of glass-ionomers and compomers, as the release of ions may increase salivary $\mathrm{pH}$ values [29]. Some researchers also suggest that some molecules-e.g., alcohol in wine-may penetrate the resin matrix, which will further accelerate the whole process [30].

For compomers, the change in color was more pronounced than for the composites, especially by the end of the experiment. Material S5 suffered slight or clearly perceptible color changes for most of the staining liquids, while wine caused pronounced color change in two different colors. At the same time, materials S4 and S6 suffered pronounced color change for five and four staining liquids, respectively, including currant juice and tea with sugar. Interestingly, imperceptible color differences were recorded in two staining liquids for S4 and only one staining liquid for S5 and S6. However, these materials are mainly indicated for particular cases, e.g., when caries control is required at the highest level possible [31].

The majority of the tested dental materials, composites and compomers included, became redder upon staining. The contribution of red was larger than that of the green color. This was the case for various staining liquids, including tea, tea with sugar, wine, coffee, currant juice, and Coca-Cola ${ }^{\circledR}$. Note that the negative values of $\Delta a$ associated to increased green color contribution are rather low for any combination of staining liquid and dental material. Furthermore, most of the materials became more yellow upon staining. Positive values of $\Delta b$ were usually larger than any negative values. This implies larger yellow color contributions as opposed to blue color, upon immersion into wine, tea, tea with sugar, coffee, coffee with sugar, soy sauce, and orange juice. However, it seems that not only extrinsic factors may be associated with it, but also the concentration of photoinitiators (e.g., tertiary amines) or their degradation may contribute to it significantly, which has been proven by Schneider et al. [32].

Nevertheless, in clinical conditions, the issue of color will be also influenced by a variety of patient-related factors, such as inappropriate dietary habits, addictions (smoking, vaping), and poor oral hygiene [12,33]. At this point, it may be worth remembering that even certain mouth rinses may cause the material to deteriorate due to color change. That is why the issue and research into dental material color stability is a multifaceted issue that requires further studies in order to allow dental clinicians to provide the best dental care, even to the most demanding patients.

\section{Conclusions}

In our in vitro studies the samples of examined materials did not undergo any hygienic procedures, and also were not influenced by any diet type or amount of food. However, the limitations described above do not render our results invalid. The methodology we used employs exposure times commonly accepted for the investigation of chemical and physical properties of dental materials-their strength, chemical stability, and, i.e., color change. It seems reasonable to continue investigations aimed at recognizing mechanisms of loss of color stability of dental materials, especially composites and compomers, as they are the most widely used materials in daily dental practice. The direction of other research studies should include both professional oral hygiene procedures, as well as the influence of salivary components, such as, e.g., enzymes. As it has been shown that several of them may influence color stability of composite resin-based dental restorative materials, it could be worth to take a closer look at their influence in the in vitro environment first and the clinical environment later. As the 
environment of the oral cavity exhibits significant differences not only among individual patients but also over time, other trials are recommended.

The outcomes of all research studies may become beneficial both for the clinicians, and the patients. Thanks to them, it may be much easier for dental professionals to choose the most appropriate material for each clinical situation. Color stability may be highly beneficial for patients, as restoration discoloration constitutes a reason for restoration replacement, as it may suggest in a misleading way that the caries process remains active in the patient. That is why materials whose color remains the same over time may prevent the patient from an unnecessary loss of tooth structure over time, and, therefore, to retain their own teeth for as long as possible. All these factors have significant importance in the contemporary patient-centered management strategies of dental caries and trauma.

Author Contributions: Conceptualization, M.S.; data curation, M.G., K.G., and M.S.; formal analysis, M.G., K.G., W.E., E.P., and M.S.; funding acquisition, M.S.; investigation, M.G. and K.G.; methodology, M.G., K.G., B.C., and M.S.; project administration, M.G., K.G., B.C., E.P., and M.S.; software, W.E. and M.S.; supervision, B.C. and M.S.; validation, M.S.; visualization, M.G., K.G., W.E., B.C., E.P., and M.S.; writing-original draft, M.G., K.G., and W.E.; writing-review and editing, W.E., B.C., E.P., and M.S. All authors have read and agreed to the published version of the manuscript.

Funding: This research received no external funding.

Acknowledgments: The authors would like to thank Igor Khmelinskii (Universidade do Algarve, Campus de Gambelas, Faro, Portugal), Mateusz Gierszewski (Faculty of Chemistry, Adam Mickiewicz University, Poznań, Poland), Joanna Maćkowiak, and Martyna Szelag for their support and help with the technical aspects of the study.

Conflicts of Interest: The authors declare no conflict of interest. The funders had no role in the design of the study; in the collection, analyses, or interpretation of data; in the writing of the manuscript, or in the decision to publish the results.

\section{References}

1. Yamamoto, M. Value conversion system-A new procedure for modification of ceramic color under special conditions of color brightness (1). Quintessenz Zahntech. 1991, 17, 929-962. [PubMed]

2. Yamamoto, M. Value conversion system-A new procedure for modification of ceramic color under special conditions of color brightness (2). Quintessenz Zahntech. 1991, 17, 1067-1087. [PubMed]

3. Stokman, H.M.G.; Gevers, T.; Koenderink, J.J. Color measurement by imaging spectrometry. Comput. Vis. Image Underst. 2000, 79, 236-249. [CrossRef]

4. Knispel, G. Factors affecting the process of color matching restorative materials to natural teeth. Quintessence Int. 1991, 22, 525-531. [PubMed]

5. Tung, F.F.; Goldstein, G.R.; Jang, S.; Hittelman, E. The repeatability of an intraoral dental colorimeter. J. Prosthet. Dent. 2002, 88, 585-590. [CrossRef] [PubMed]

6. Haselton, D.R.; Diaz-Arnold, A.M.; Dawson, D.V. Color stability of provisional crown and fixed partial denture resins. J. Prosthet. Dent. 2005, 93, 70-75. [CrossRef]

7. Kolbeck, C.; Rosentritt, M.; Lang, R.; Handel, G. Discoloration of facing and restorative composites by UV-irradiation and staining food. Dent. Mater. 2006, 22, 63-68. [CrossRef]

8. Janda, R.; Roulet, J.; Latta, M.; Steffin, G.; Rüttermann, S. Color stability of resin-based filling materials after aging when cured with plasma or halogen light. Eur. J. Oral Sci. 2005, 113, 251-257. [CrossRef]

9. Guan, Y.H.; Lath, D.L.; Lilley, T.H.; Willmot, D.R.; Marlow, I.; Brook, A.H. The measurement of tooth whiteness by image analysis and spectrophotometry: A comparison. J. Oral Rehabil. 2005, 32, 7-15. [CrossRef]

10. Ikeda, T.; Sidhu, S.K.; Omata, Y.; Fujita, M.; Sano, H. Colour and translucency of opaque-shades and body-shades of resin composites. Eur. J. Oral Sci. 2005, 113, 170-173. [CrossRef]

11. Reich, S.; Hornberger, H. The effect of multicolored machinable ceramics on the esthetics of all-ceramic crowns. J. Prosthet. Dent. 2002, 88, 44-49. [CrossRef] [PubMed]

12. Ertas, E.; Gueler, A.U.; Yuecel, A.C.; Koepruelue, H.; Gueler, E. Color stability of resin composites after immersion in different drinks. Dent. Mater. J. 2006, 25, 371-376. [CrossRef] [PubMed]

13. Guler, A.U.; Yilmaz, F.; Kulunk, T.; Guler, E.; Kurt, S. Effects of different drinks on stainability of resin composite provisional restorative materials. J. Prosthet. Dent. 2005, 94, 118-124. [CrossRef] 
14. Ertan, A.A.; Şahin, E. Colour stability of low fusing porcelains: An in vitro study. J. Oral Rehabil. 2005, 32, 358-361. [CrossRef] [PubMed]

15. Cal, E.; Güneri, P.; Kose, T. Comparison of digital and spectrophotometric measurements of colour shade guides. J. Oral Rehabil. 2006, 33, 221-228. [CrossRef]

16. Villalta, P.; Lu, H.; Okte, Z.; Garcia-Godoy, F.; Powers, J.M. Effects of staining and bleaching on color change of dental composite resins. J. Prosthet. Dent. 2006, 95, 137-142. [CrossRef]

17. Paolone, G.; Orsini, G.; Manauta, J.; Devoto, W.; Putignano, A. Composite shade guides and color matching. Int. J. Esthet. Dent. 2014, 9, 164-182.

18. Akbulut, M.B.; Uyar Arpaci, P.; Unverdi Eldeniz, A. Effects of novel root repair materials on attachment and morphological behaviour of periodontal ligament fibroblasts: Scanning electron microscopy observation. Microsc. Res. Tech. 2016, 79, 1214-1221. [CrossRef]

19. Yoon, M.; Kim, J.-S.; Yoo, S.-H. Changes of compressive strength and microhardness of composite resin, giomer and compomer after thermocycling treatment. J. Korean Acad. Pediatr. Dent. 2010, 37, 438-444.

20. Ayad, N.M. Susceptibility of restorative materials to staining by common beverages: An in vitro study. Eur. J. Esthet. Dent. 2007, 2, 236-247.

21. Poggio, C.; Ceci, M.; Beltrami, R.; Mirando, M.; Wassim, J.; Colombo, M. Color stability of esthetic restorative materials: A spectrophotometric analysis. Acta Biomater. Odontol. Scand. 2016, 2, 95-101. [CrossRef] [PubMed]

22. Falkensammer, F.; Arnetzl, G.V.; Wildburger, A.; Freudenthaler, J. Color stability of different composite resin materials. J. Prosthet. Dent. 2013, 109, 378-383. [CrossRef]

23. Barutcigil, Ç.; Yıldız, M. Intrinsic and extrinsic discoloration of dimethacrylate and silorane based composites. J. Dent. 2012, 40, e57-e63. [CrossRef] [PubMed]

24. Kumari, R.V.; Nagaraj, H.; Siddaraju, K.; Poluri, R.K. Evaluation of the effect of surface polishing, oral beverages and food colorants on color stability and surface roughness of nanocomposite resins. J. Int. Oral Health 2015, 7, 63-70. [PubMed]

25. Bagheri, R.; Burrow, M.F.; Tyas, M. Influence of food-simulating solutions and surface finish on susceptibility to staining of aesthetic restorative materials. J. Dent. 2005, 33, 389-398. [CrossRef] [PubMed]

26. Ren, Y.-F.; Feng, L.; Serban, D.; Malmstrom, H.S. Effects of common beverage colorants on color stability of dental composite resins: The utility of a thermocycling stain challenge model in vitro. J. Dent. 2012, 40, e48-e56. [CrossRef]

27. Alandia-Roman, C.C.; Cruvinel, D.R.; Sousa, A.B.S.; Pires-de-Souza, F.C.P.; Panzeri, H. Effect of cigarette smoke on color stability and surface roughness of dental composites. J. Dent. 2013, 41, e73-e79. [CrossRef]

28. Azer, S.S.; Hague, A.L.; Johnston, W.M. Effect of $\mathrm{pH}$ on tooth discoloration from food colorant in vitro. J. Dent. 2010, 38, e106-e109. [CrossRef]

29. Nicholson, J.W.; Aggarwal, A.; Czarnecka, B.; Limanowska-Shaw, H. The rate of change of pH of lactic acid exposed to glass-ionomer dental cements. Biomaterials 2000, 21, 1989-1993. [CrossRef]

30. Catelan, A.; Briso, A.L.F.; Sundfeld, R.H.; Goiato, M.C.; dos Santos, P.H. Color stability of sealed composite resin restorative materials after ultraviolet artificial aging and immersion in staining solutions. J. Prosthet. Dent. 2011, 105, 236-241. [CrossRef]

31. Barutcigil, Ç.; Harorli, O.T.; Yildiz, M.; Özcan, E.; Arslan, H.; Bayindir, F. The color differences of direct esthetic restorative materials after setting and compared with a shade guide. J. Am. Dent. Assoc. 2011, 142, 658-665. [CrossRef] [PubMed]

32. Schneider, L.F.J.; Pfeifer, C.S.C.; Consani, S.; Prahl, S.A.; Ferracane, J.L. Influence of photoinitiator type on the rate of polymerization, degree of conversion, hardness and yellowing of dental resin composites. Dent. Mater. 2008, 24, 1169-1177. [CrossRef] [PubMed]

33. Gawriołek, M.; Sikorska, E.; Ferreira, L.F.V.; Costa, A.I.; Khmelinskii, I.; Krawczyk, A.; Sikorski, M.; Koczorowski, P.R. Color and luminescence stability of selected dental materials in vitro. J. Prosthodont. Implant. Esthet. Reconstr. Dent. 2012, 21, 112-122. [CrossRef] [PubMed]

(C) 2020 by the authors. Licensee MDPI, Basel, Switzerland. This article is an open access article distributed under the terms and conditions of the Creative Commons Attribution (CC BY) license (http://creativecommons.org/licenses/by/4.0/). 